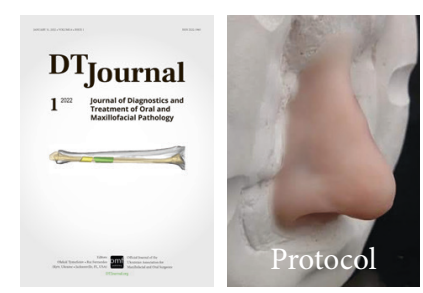

\title{
Surgical Reconstruction and Rehabilitation of Midface Defects using Osseointegrated Implant- supported Maxillofacial Prosthetics
}

John M. Le ${ }^{a, *}$, Yedeh P. Ying ${ }^{b}$, Michael T. Kase, \& Anthony B. Morlandt

\begin{abstract}
Midface defects can be life-changing, both functionally and psychologically, for the affected patient. Additionally, restoration of form, function, and aesthetics can be challenging for the reconstructive surgeon. For defects affecting facial subunits such as the nose and orbit, a maxillofacial prosthetic can both obturate the defect and achieve aesthetically pleasing outcomes. Osseointegrated implants placed into sound bone at the defect site allow the maxillofacial prosthodontist to optimize prosthesis retention without the need for adhesive or a mechanical device. In this article, we will share our multidisciplinary treatment protocol and outcome for addressing large midface defects using osseointegrated implant-retained maxillofacial prosthetics. Finally, we will also share our experience and challenges in the incorporation of digital technology in the prosthetic processes of the treatment plan. In the evolving digital age, rapid prototyping technologies have provided the reconstructive surgeon and maxillofacial prosthodontist the ability to accurately plan and execute predictable and reproducible results for a complex array of maxillofacial defects.
\end{abstract}

a DDS MD; Resident, Department of Oral and Maxillofacial Surgery School of Dentistry, University of Alabama at Birmingham, Birmingham, AL 35233, USA.

E-mail: johnmtle@gmail.com

b DMD MD FACS; Assistant Professor, Section of Oral Oncology Department of Oral and Maxillofacial Surgery, School of Dentistry, University of Alabama at Birmingham, Birmingham, AL 35233, USA. E-mail: yying@uabmc.edu

c DMD; Assistant Professor, Department of Maxillofacial Prosthodontics School of Dentistry, University of Alabama at Birmingham, Birmingham, AL 35233, USA.

E-mail:mkase@uabmc.edu

' DDS MD FACS; Associate Professor, Chief Section of Oral Oncology, Department of Oral and Maxillofacial Surgery - School of Dentistry, University of Alabama at Birmingham, Birmingham, AL 35233, USA.

E-mail: morlandt@uab.edu

* Correspondence: John M. Le, Department of Oral and Maxillofacial Surgery, School of Dentistry, University of Alabama at Birmingham, SDB 419, 1919 7th Ave S, Birmingham, AL 35233, USA.

E-mail: johnmtle@gmail.com

ORCID: https://orcid.org/0000-0002-4836-2487

Instagram: @surgeon foodie

ResearchGate: https://www.researchgate.net/profile/John-Le-9
Please cite this article as: Le JM, Ying YP, Kase MT, Morlandt AB. Surgical reconstruction and rehabilitation of midface defects using osseointegrated implant-supported maxillofacial prosthetics. J Diagn Treat Oral Maxillofac Pathol 2022;6(1):9-25.

The word 'Protocol' at the upper right icon means that article highlights treatment protocol.

Paper received 11 January 2022

Accepted 25 January 2022

Available online 26 January 2022

https://doi.org/10.23999/j.dtomp.2022.1.4

(c) 2022 OMF Publishing, LLC. This is an open access article under the CC BY license (http://creativecommons.org/licenses/by-nc/4.0/). 


\section{INTRODUCTION}

Maxillofacial defects involving the midface secondary to trauma or tumor surgery can be challenging to reconstruct and often requires a multi-staged surgical approach where local and/ or distant vascularized tissue are needed to restore form, function, and aesthetics of the missing facial subunit(s). This is especially true when multiple tissue types such as skin, cartilage, and bone are missing. ${ }^{1}$ Therefore, a successful reconstructive outcome will not only re-establish aesthetic facial form and function, but also aid in psychosocial reintegration for the patient. ${ }^{2,3}$ Several midface defect classification systems have been published; however, none are universally applied. Two popular classification systems have been described in the literature. ${ }^{4,5}$ In this article, we will use the Brown-Shaw classification system, a Liverpool-based system focusing on both prosthetic and cosmetic aspects of reconstruction which may be used to select both local and free flaps for each defect type (Fig 1). Based on this classification system, several fasciocutaneous and/or osteocutaneous vascularized free flaps can effectively obliterate the defect and may provide sufficient bone to house dental implants. ${ }^{4}$. However, these surgeries are often long and often requiring multiple additional surgeries over an extended time to achieve aesthetically pleasing results. ${ }^{6}$ On the other hand, prosthetic rehabilitation can provide an alternative shorter and simpler treatment option, lower initial cost, possibility for immediate new dentition, and ease for oncologic surveillance. Currently, in a selected group of patients, the combination of reconstructive surgery with osseointegrated implant placement followed by prosthetic rehabilitation is commonly recommended at our institution for large midface defects involving multiple facial subunits as it results in the best outcome for restoration of form, function, and aesthetics. Our patient selection is limited by the costs associated with the prosthesis and the patient's commitment to follow through with the treatment.

Attempts to replace and restore maxillofacial defects using solely prosthetics have dated back centuries with reports in the historical records and texts. ${ }^{8}$ Traditionally, adhesive alone or in addition to a mechanical device (e.g., glasses) was used for retention and camouflage of prosthesis margins (Figs 2 and 3). Following the introduction of osseointegrated implants for dental rehabilitation in the late 1970s by P.I. Branemark, ${ }^{9}$ its application was expanded outside the oral cavity and onto the craniomaxillofacial complex. ${ }^{10}$ With the success rate of $90-95 \%$ over a 10 -year period, the stability and predictability of the osseointegrated implant has become the promising treatment option for dental rehabilitation and provides better retention for maxillofacial prostheses without the need for adhesive agents. ${ }^{3,11}$ It also aids the patient in positioning the prosthesis accurately; thus, resulting in a better clinical and psychosocial outcome. ${ }^{12-14}$
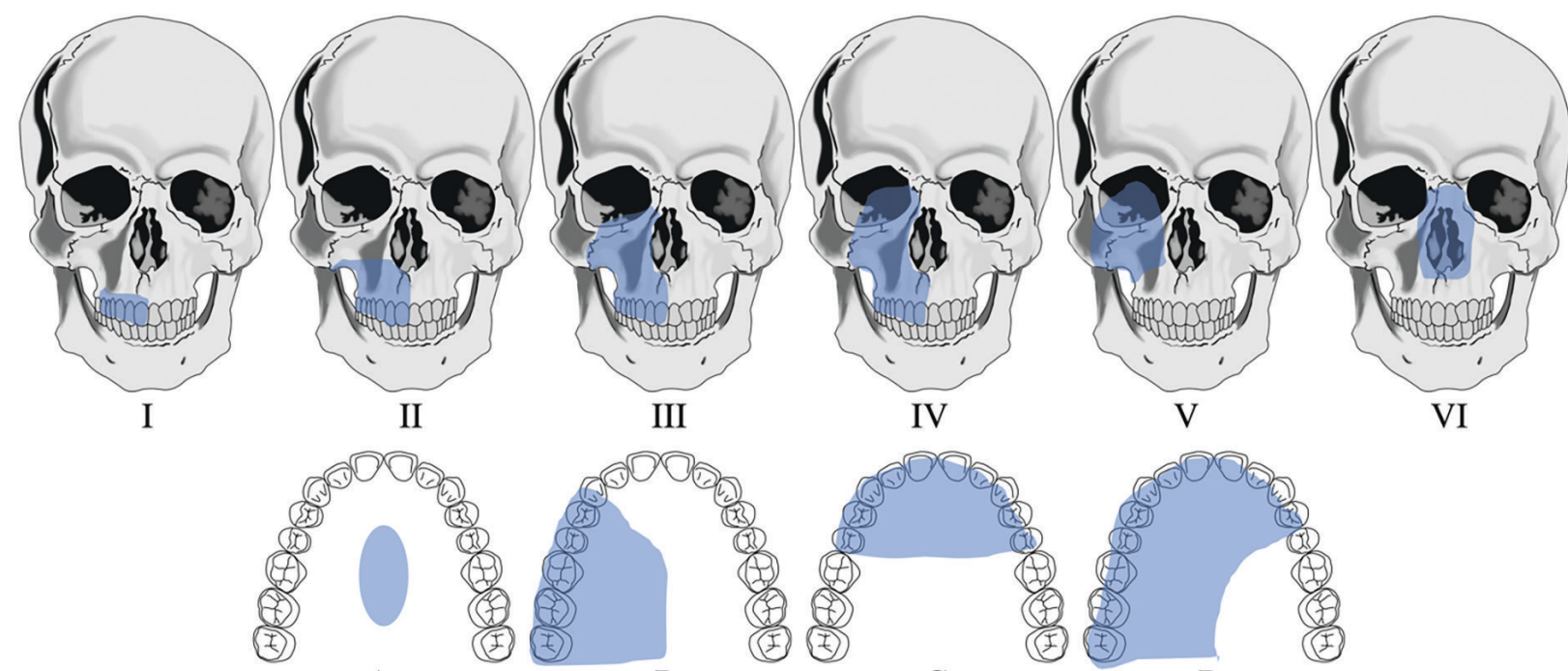

A

B
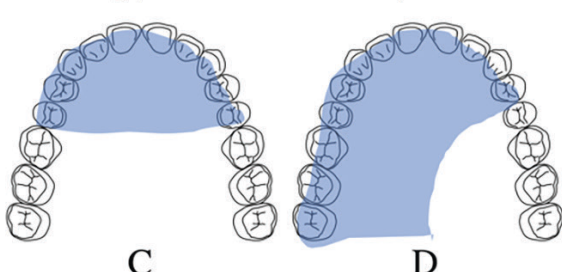

VI

FIGURE 1. Brown and Shaw Maxilla and Midface Defect Classification. 


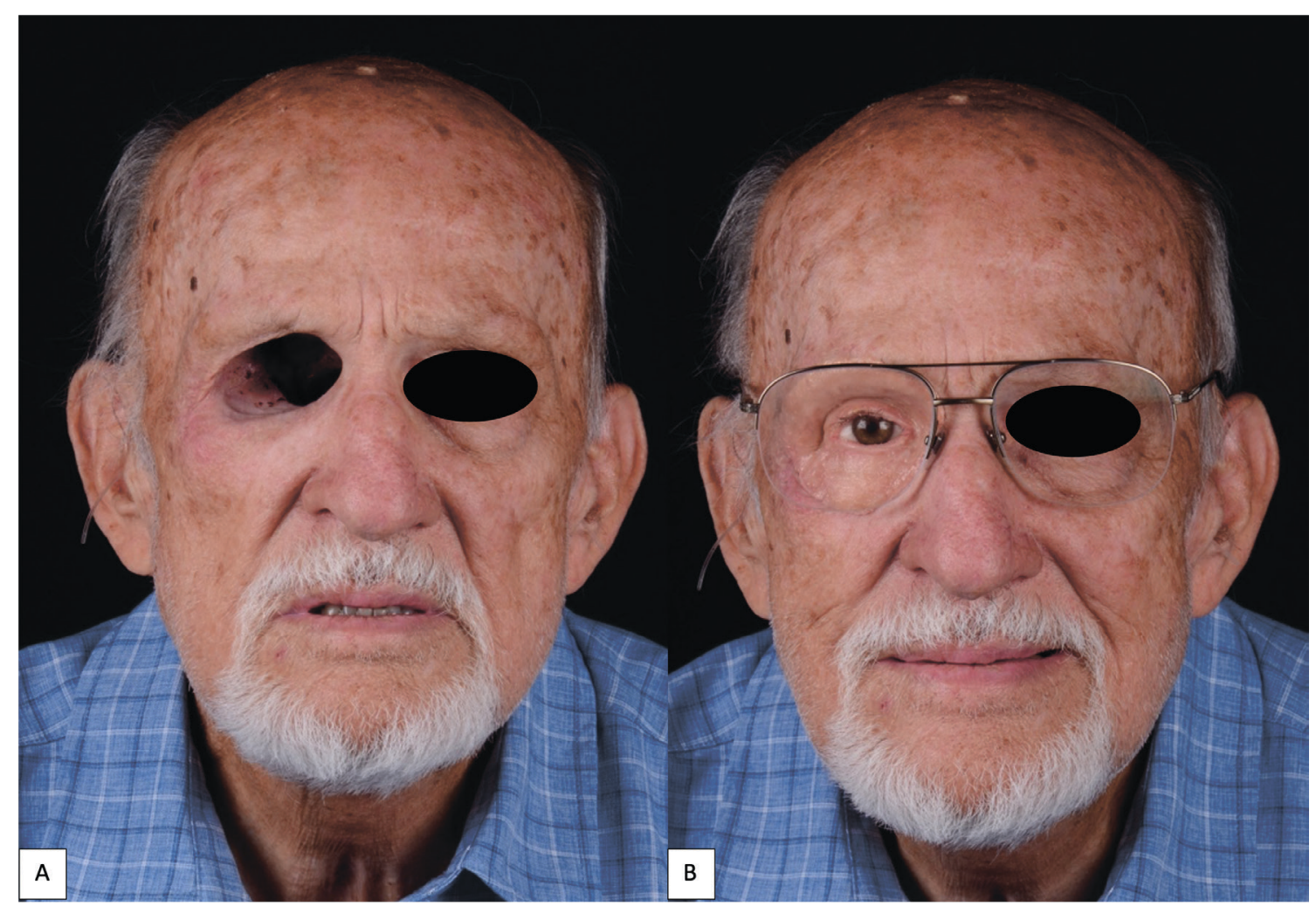

FIGURE 2. Orbital defect (A) with prosthesis and eyeglasses (B).

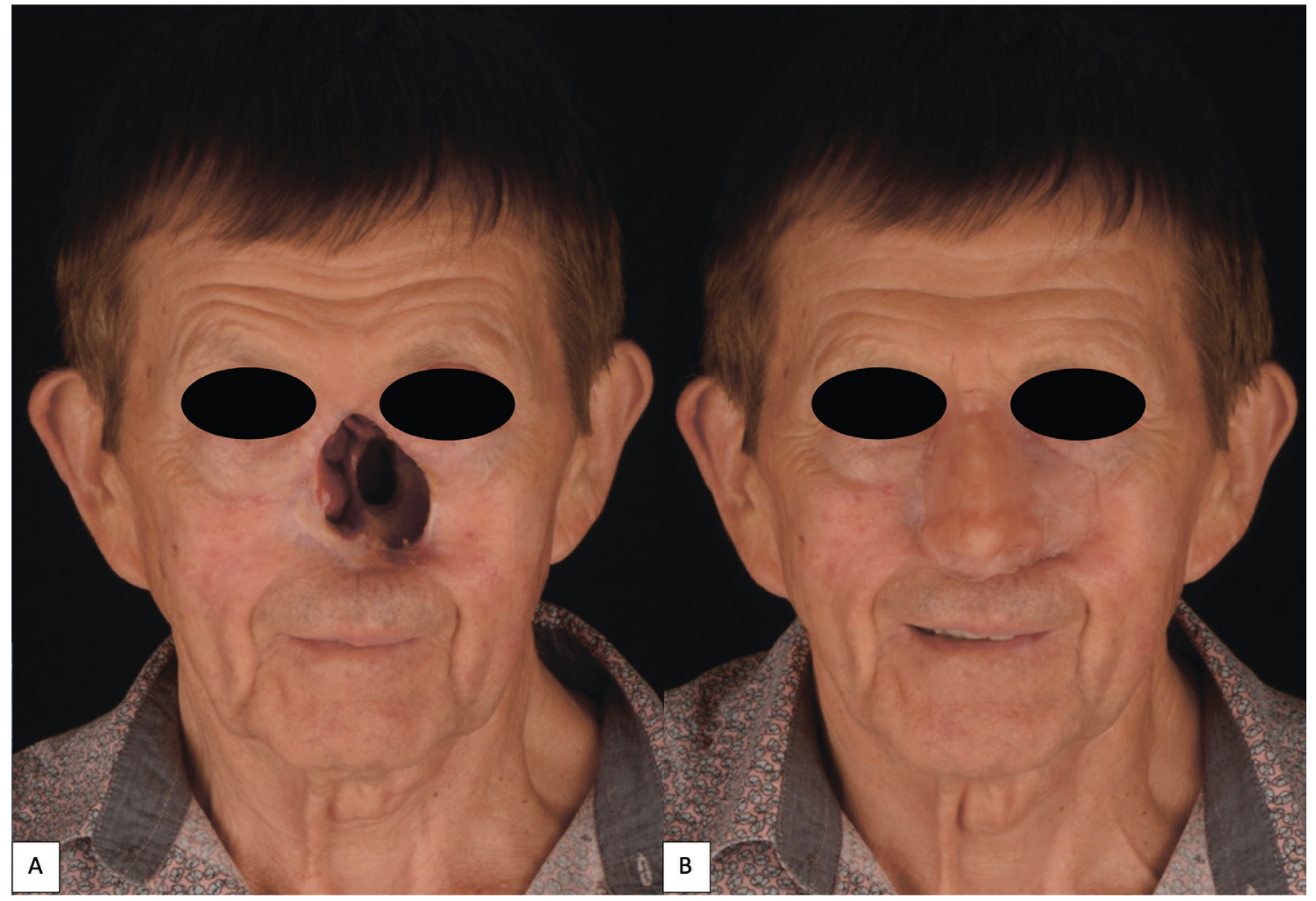

FIGURE 3. Nasal defect (A) with prosthesis in place (B). 
Prosthetic rehabilitation of maxillofacial defects may provide several advantages for both the reconstructive surgeon and patient. Aside from providing good aesthetic outcomes for large facial defects that involve multiple facial subunits, it allows for visually accessible surveillance in oncologic cases. In addition, for patients requiring adjuvant radiotherapy, the risk for post-radiation wound healing complications (i.e., impaired wound healing, osteoradionecrosis) is greater in patients who undergo reconstructive surgery using local tissue in an irradiated field. ${ }^{15-18}$ Therefore, to avoid these complications, if needed, implants are often treatment planned to be placed at the time of tumor extirpation and/or prior to adjuvant radiation therapy. Osseointegration of the implant(s) is evaluated clinically and radiographically at least 4 months post-operatively and then uncovered to initiate the prosthetic treatment process. ${ }^{2,3,19}$

\section{CLINICAL EVALUATION AND TREATMENT PLANNING}

Both primary referrals for benign and malignant oral and maxillofacial pathology and secondary referrals for reconstruction of maxillofacial defects are evaluated in our clinic by a multidisciplinary team of ablative and reconstructive surgeons and a maxillofacial prosthodontist. This clinical evaluation is especially crucial since the dentition and/or facial anatomy will be altered after the ablative surgery. For patients who need tumor resection and reconstruction, the appropriate $\mathrm{CT}$ imaging are obtained per American Joint Committee on Cancer (AJCC) guidelines to determine surgical margins. For patients who are referred for reconstructive surgery only, a CT maxillofacial and Panorex radiograph are obtained to evaluate the existing bone substructure and dentition for reconstruction using one of more of the following: allogenic bone graft, autologous vascularized tissue (non-osseous and osseous), and osseointegrated implants.

In our case series, we describe our surgical approach for dental and maxillofacial rehabilitation using osseointegrated implants for Brown's Class III-VI midface defects. Class I defects present as an intra-oral defect and can be treated using a dental prosthesis or reconstructed using a local or free flap. ${ }^{4}$ However, when there are no contraindications for a microvascular free flap, the fasciocutaneous radial forearm serves as an excellent reconstructive solution to obturate a Class I or II defect, but rarely can support a dental prosthesis without the placement of osseointegrated implants in the bony substructure. Therefore, for long-spanning Class II defects, the vascularized osteocutaneous fibula free flap serves as an excellent reconstructive option as it can both obturate the dead space as well as house osseointegrated implants for dental rehabilitation. ${ }^{20}$ For Class V defects, either a pedicled or soft tissue free flap can obturate the dead space. However, for this specific type of defect class, the anatomical boundary of the defect provides the ideal retention for an orbital prosthesis. For the cases presented in this article, all the osseointegrated implants were placed free-handed. The number, location, and angulation of the implants placed were decided intraoperatively by the reconstructive surgeon according to the bone quantity and quality available. Both traditional labbased and digital-based technologies were used for the prosthetic portion of the study cohort. Finally, we will highlight the challenges and limitations that we encountered during the treatment process.

\section{CASE REPORTS}

\section{Case 1: Brown's Class IIIC}

We previously described a case of a 68 -year-old male that underwent a total rhinectomy, partial maxillectomy, and partial excision of the upper lip due to recurrent basal cell carcinoma (BCC) of the nose and was treated with horizontally placed zygomatic implants and a multi-component extra- and intraoral prosthesis (Fig 4). ${ }^{21}$ Traditional impression techniques were used to replicate the midface defect and wax up. The stone model impressions were then digitized, 3-D printed, and used for the design of the implant-facial prosthesis abutment connector, and final silicone prosthesis staining (Fig 5).

\section{Case 2: Brown's Class IVD}

A 71-year-old male with a history of advanced stage oral squamous cell carcinoma of the left maxilla diagnosed in 2013 who underwent primary proton and chemotherapy followed by a total maxillectomy, partial rhinectomy, excision of facial skin, neck dissection and reconstruction with latissimus dorsi free flap in 2014. He then underwent 


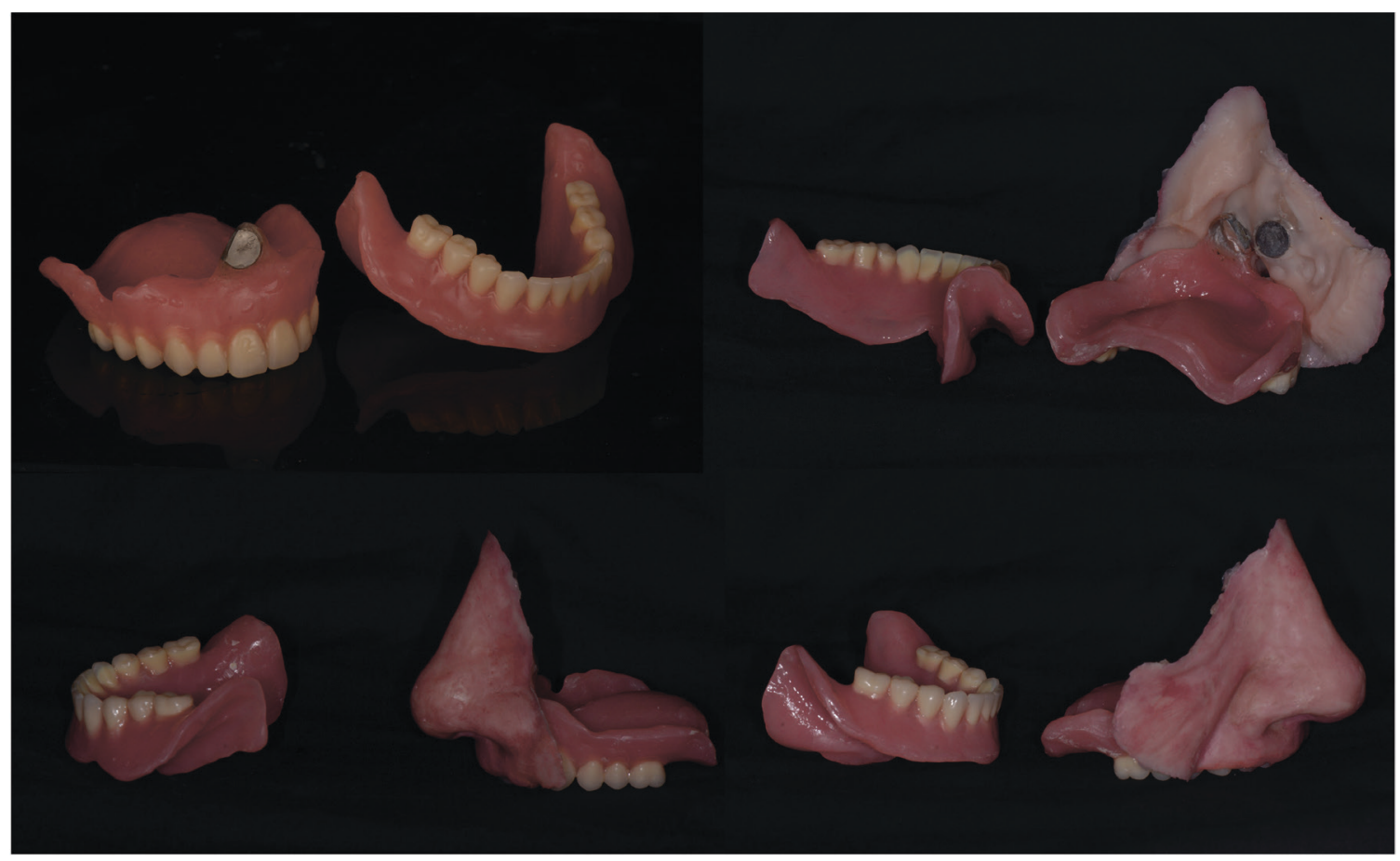

FIGURE 4. Case 1. Anterior, posterior, and lateral views of the final upper and lower dentures with the magnetic component located at the superior and middle portion of the maxillary denture and inner nasal portion of the silicone prosthesis.

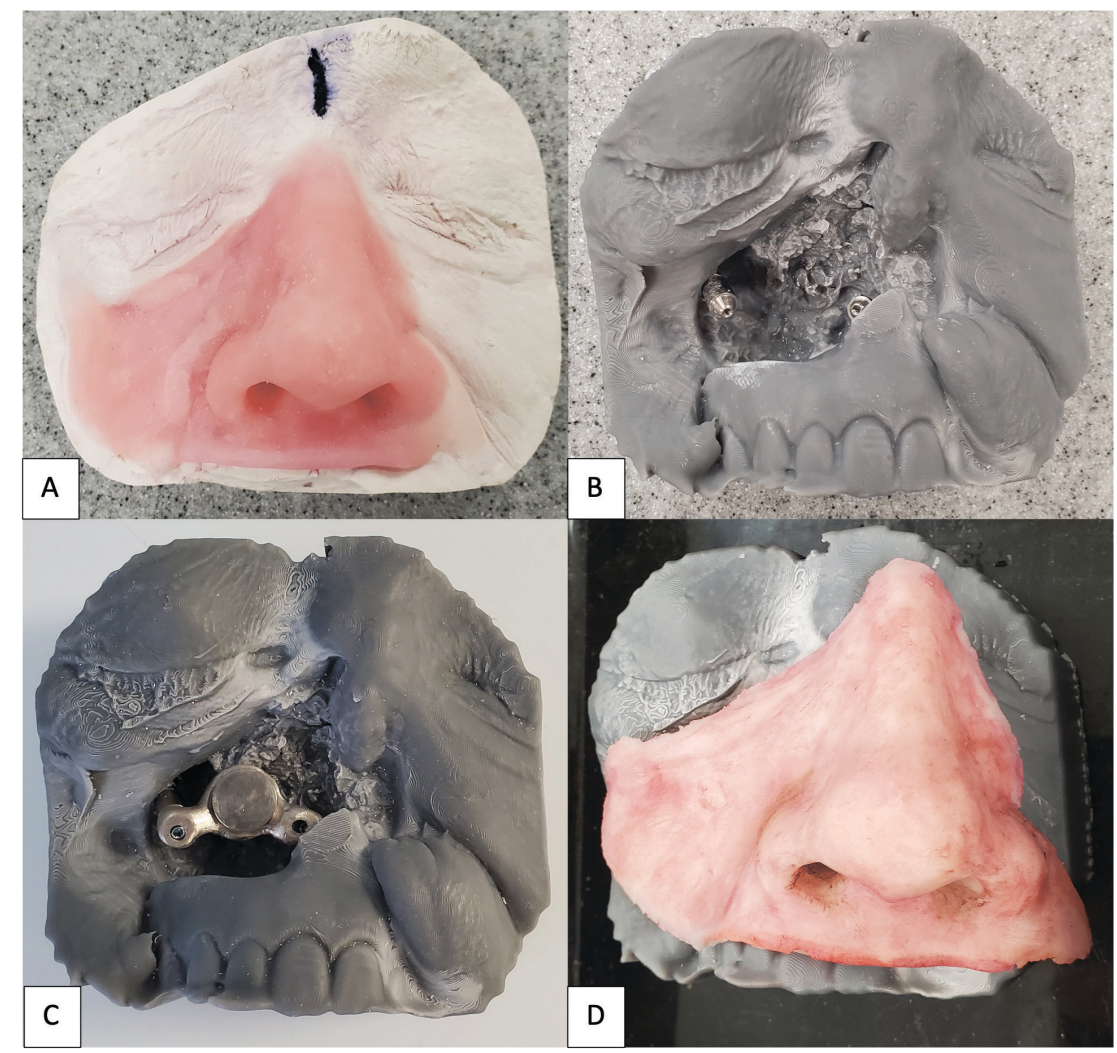

FIGURE 5. Case 1. Stone case and wax-up (A). 3D-printed model with implant abutments in place (B), magnetic connector in place $(\mathbf{C})$, and silicone prosthesis attached (D). 
three additional vascularized free tissue transfers (osteocutaneous fibula, anterior lateral thigh, and fasciocutaneous radial forearm) and skin grafting procedures from 2016 to 2019 to reconstruct the maxilla and restore the upper lip and left malar volume. Unfortunately, the patient developed left eye blindness due to chronic exposure keratitis secondary to scar contracture and lack of periorbital tissue volume. He was then referred to our clinic for left orbital exenteration and placement of an orbital prosthesis. Due to his prior history of proton therapy and multiple free vascularized tissue transfers, we decided that placement of osseointegrated implants would be a minimally invasive reconstructive option and provide the best retention for a large orbital prosthesis. We did, however, take into consideration the risk for implant failure due the history of radiation. Following the orbital exenteration, three osseointegrated implants measuring $3.8 \mathrm{~mm} \times 9 \mathrm{~mm}$
(BioHorizons ${ }^{\circledR}$, Birmingham, AL, USA) were placed into the superior lateral orbital rim (Fig 6) because there was no additional adjacent maxillary or nasal bone thick enough to receive the implants. After 4 months postoperatively, the patient was seen by the maxillofacial prosthodontist for prosthetic fabrication. A combination of digital-based and traditional labbased techniques were utilized to fabricate the final prosthesis. Photogrammetry and Meshmixer, a 3D modeling software, were used to capture and edit the 3D image, respectively. A digital cast model was then created (Model Builder; 3Shape) and then printed using light-cured engineering resin (Form 2; Formlab) where a wax-up was completed (Fig 7). Traditional polyvinyl siloxane (PVS) impressions were used to pick up the orbital implants and adjacent anatomy to fabricate the attachment unit of the prothesis (Fig 8). The final silicone-based orbital prosthesis provided an excellent aesthetic outcome (Fig 9).

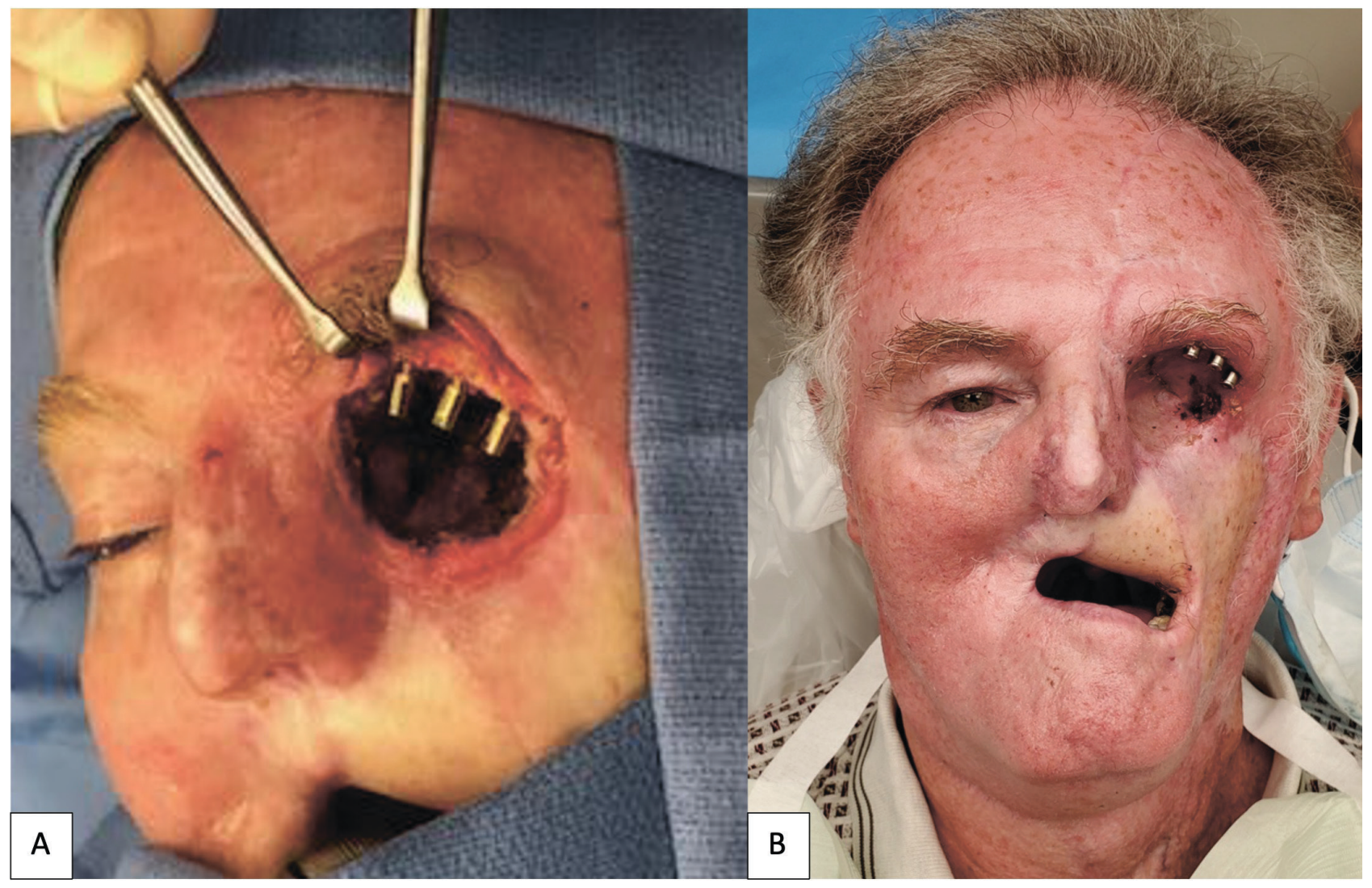

FIGURE 6. Case 2. Positioning of osseointegrated implants in the left supero-lateral orbital rim at the time placement (A), and after complete healing with impression abutments in place (B). 


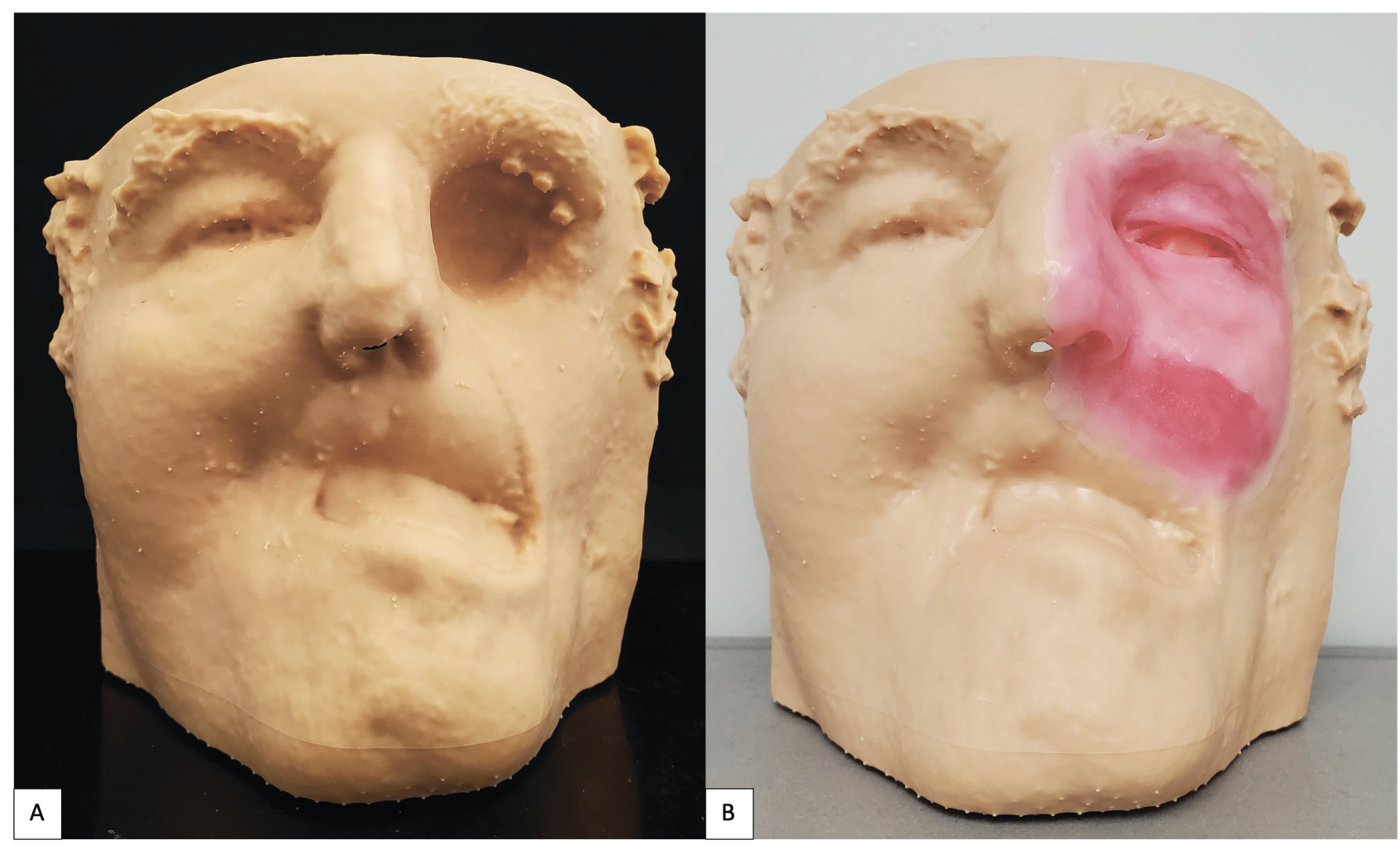

FIGURE 7. Case 2. 3D-printed resin model created from a facially scanned digital case model (A), and wax-up of the left orbit, partial nasal and malar (B).

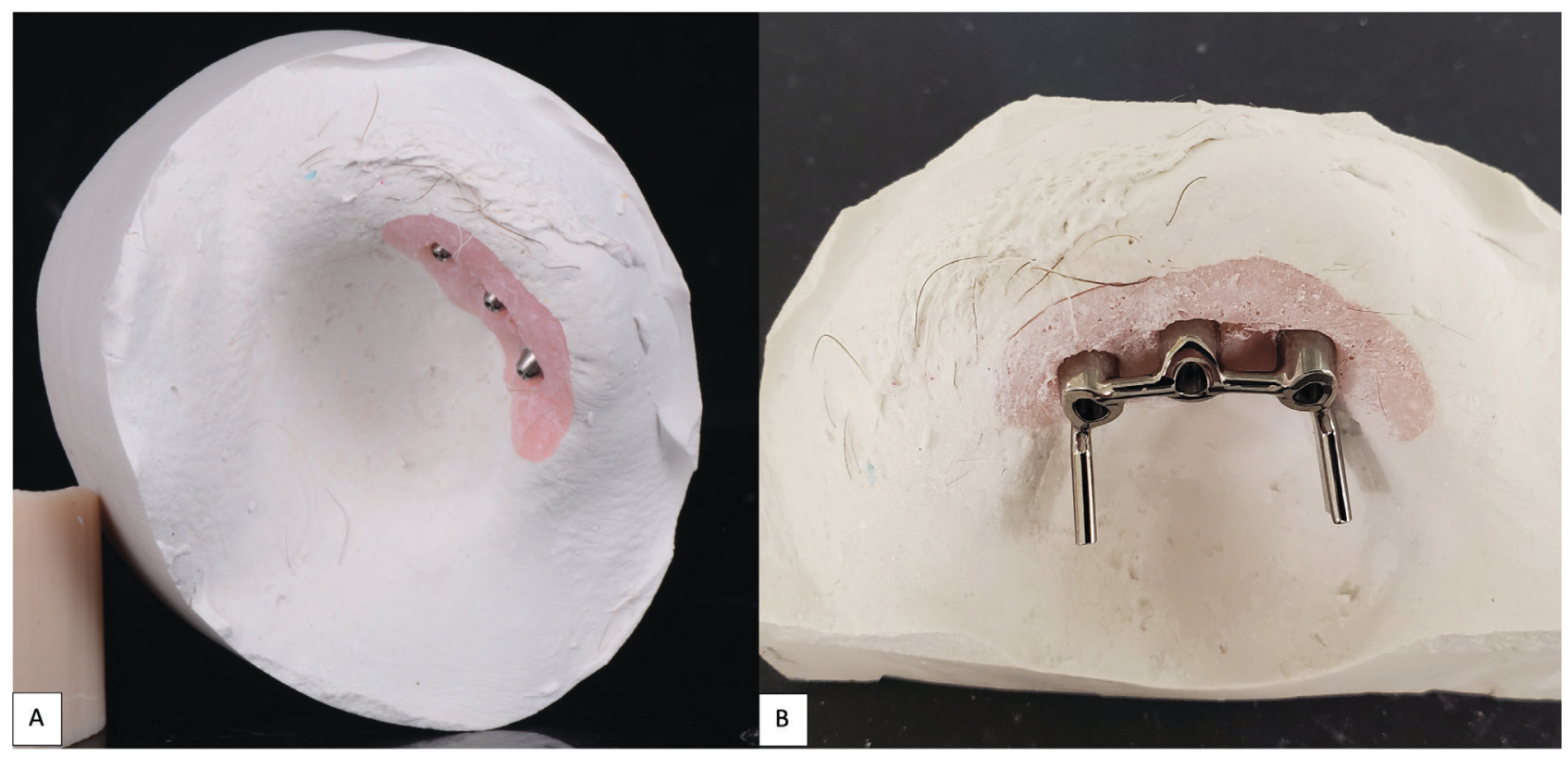

FIGURE 8. Case 2. Stone case mold of the defect with the healing abutments $(\mathbf{A})$ and bar substructure attachment in place $(\mathbf{B})$. 


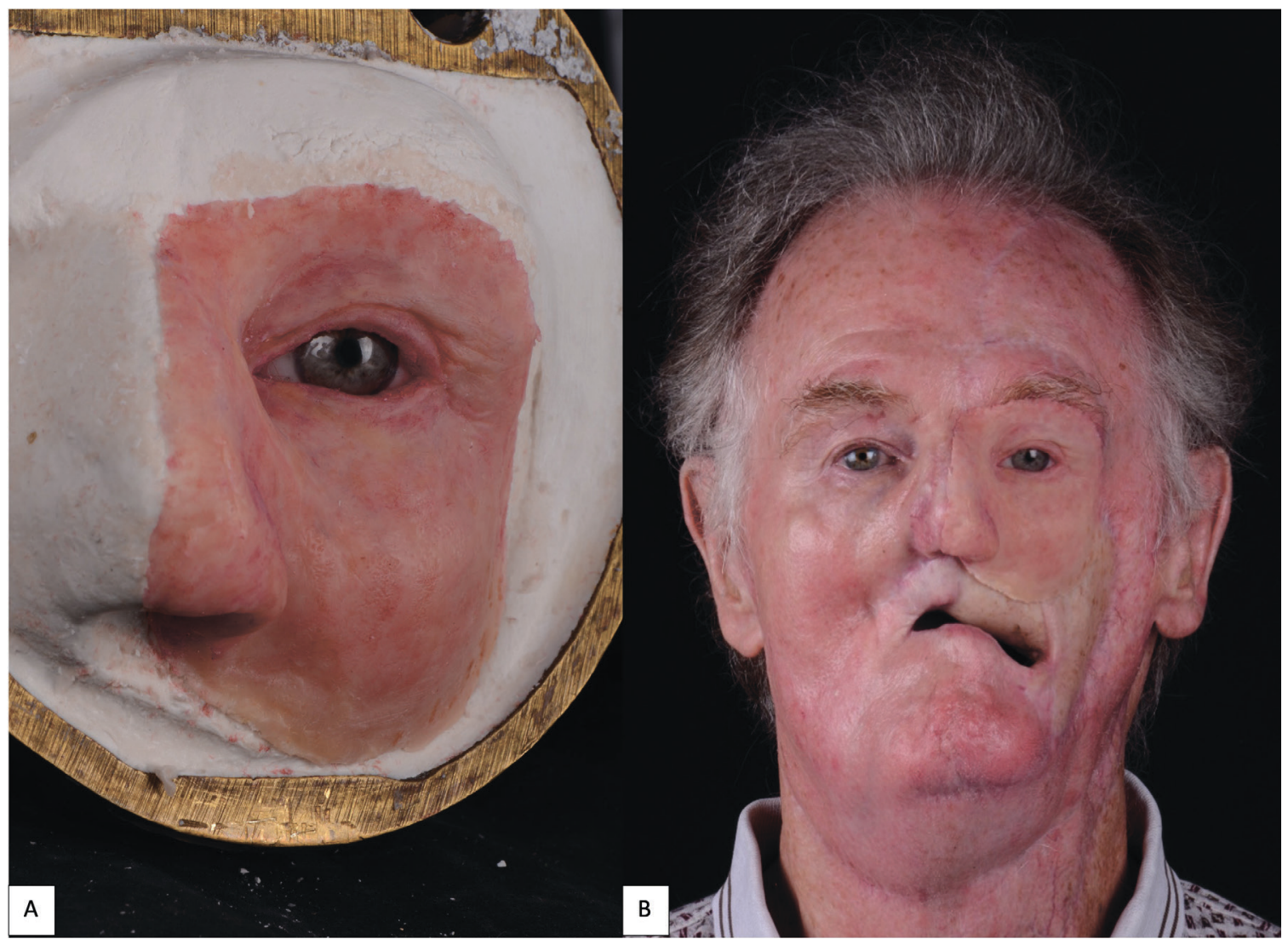

FIGURE 9. Case 2. Final touches for color staining completed on the stone case $(\mathbf{A})$, and final prosthesis placement with an excellent aesthetic outcome (B).

\section{Case 3: Brown's Class IVD}

A 63-year-old female presented to our clinic with a longstanding untreated pT3Nx basal cell carcinoma that initially started at the nasal alar crease and treated with topical ointments prescribed by a homeopathic doctor. Unfortunately, the tumor continued to progress for nearly 10 years prior to her seeking surgical treatment. When she presented to our clinic, the tumor had eroded her entire midface (right lower lid, right malar, upper lip, underlying maxilla, and complete nose). Due to the size of the tumor and the extent of its infiltration into the surrounding hard and soft tissue structures, the patient underwent a radical maxillectomy, right orbital exenteration, total rhinectomy, excision of facial skin, and reconstruction with a vascularized anterior lateral thigh (ALT) to obturate the right maxillary sinus space. The surgical margins and extent of the resection are shown in a 3-D reconstruction CT image of the face (Fig 10). Fortunately, adjuvant radiotherapy was not indicated based on the final pathological staging. With no evidence of disease at the one-year mark confirmed with MRI, the patient was evaluated by the maxillofacial prosthodontist for dental and facial prosthetic rehabilitation via the placement of osseointegrated implants into the remaining maxillofacial bones. The patient received 6 osseointegrated implants (BioHorizons ${ }^{\circledR}$, Birmingham, AL, USA) were placed in conjunction with flap debulking and recontouring of the soft tissue around the right orbit. Two implants were placed into the supero-lateral orbital rim $(3.8 \mathrm{~mm}$ $\times 9 \mathrm{~mm}), 1$ was placed into the glabella $(3.8 \mathrm{~mm} \times$ $9 \mathrm{~mm}), 2$ were placed into the right mandible (3.8 $\mathrm{mm} \times 10.5 \mathrm{~mm}$ ), and 1 placed into the left zygoma $(3.4 \mathrm{~mm} \times 10.5 \mathrm{~mm})$. The implants were uncovered at the 7-month mark and the patient proceeded with the prosthetic phase of treatment. Of note, the implant in the left zygoma was not incorporated into the substructure of final facial prosthesis design and did not lead to any future complications that would require its removal.

Like Case 2, both traditional lab-based and digital techniques were used to fabricate impression trays and models for the dental and facial prostheses. 


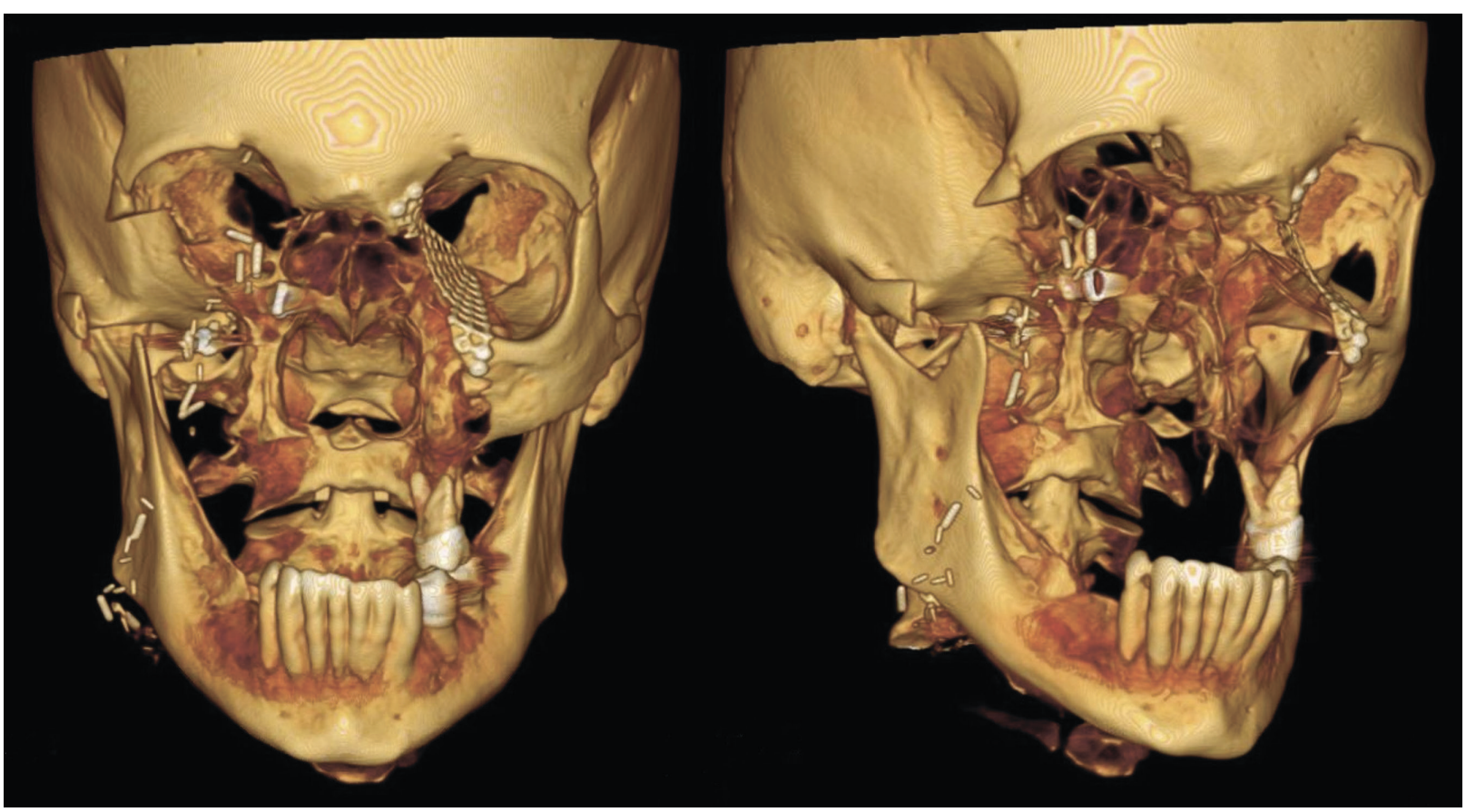

FIGURE 10. Case 3.3D reconstructed maxillofacial image of the midface defect after tumor extirpation.

A facial scanner (Sense 2 Scanner; 3D Systems) was used to assist in the designing of the custom impression trays. Localized conventional impressions using the open tray technique with polyvinyl siloxane material (Aquasil Ultra; Dentsply Sirona) were taken around the orbital and intraoral implant areas, and then poured in two separate casts using type IV dental stone (Silky-Rock Low-Expansion Die Stone; Whip Mix Corp) (Fig 11). An implant-retained prosthesis was then fabricated by designing a magnet attachment at the medial aspect of the orbit, and locator bar attachment at mandibular area, with twopiece prosthetic design in medical grade silicone (VST-50; Factor II) to allow mandibular movements. Because there was limited tongue mobility and large palatal defect, a palatal cameo surface impression was incorporated into the prosthetic substructure and as an extension of the upper lip and midface silicone component (Fig 12). At the time of final placement of the prostheses, the patient had better articulation, deglutition, and an excellent aesthetic outcome (Fig 13).

\section{Case 4: Brown's Class VI}

A 62-year-old female with a history of pT2Nx squamous cell carcinoma (SCC) of the nose was referred to our clinic after having undergone a total rhinectomy. The patient opted to have a prosthesis after having discussed the reconstructive options with her primary surgeon. After confirmation of negative surgical margins with no indications for adjuvant radiotherapy, the patient received 2 osseointegrated implants into the nasal floor of the anterior maxilla $(3.8 \mathrm{~mm} \times 13 \mathrm{~mm}$ and $3.8 \times 15 \mathrm{~mm})$ and 1 osseointegrated implant into the glabella (3.8 $\mathrm{mm} \times 9 \mathrm{~mm})($ BioHorizons $\AA$, Birmingham, $\mathrm{AL}$, USA) (Fig 14A-B). The three implants were placed at an angulation which provided a tripod-based bar attachment for the fabrication of the final prosthesis (Fig 14C). Traditional lab-based methods were used to wax up and fabricate the final nasal prosthesis (Fig 14D). Due to the angle divergence of the implant platforms and abutments, a digital bar pattern could not be outputted from the digital software. The final nasal prosthesis provided an excellent color match and aesthetic outcome for the patient (Fig 15).

In summary, for selected reconstructive cases where an implant-supported maxillofacial prosthesis is desired by the patient, our recommendations for the location of the implants to be placed based on orbital, nasal, and maxillary defects are shown in Figure 16. Generally, for cases where dental rehabilitation is also considered, it is ideal to place the implants into the existing native- or neo-mandible/maxilla (e.g., fibula free flap) to oppose the remaining dentition. 


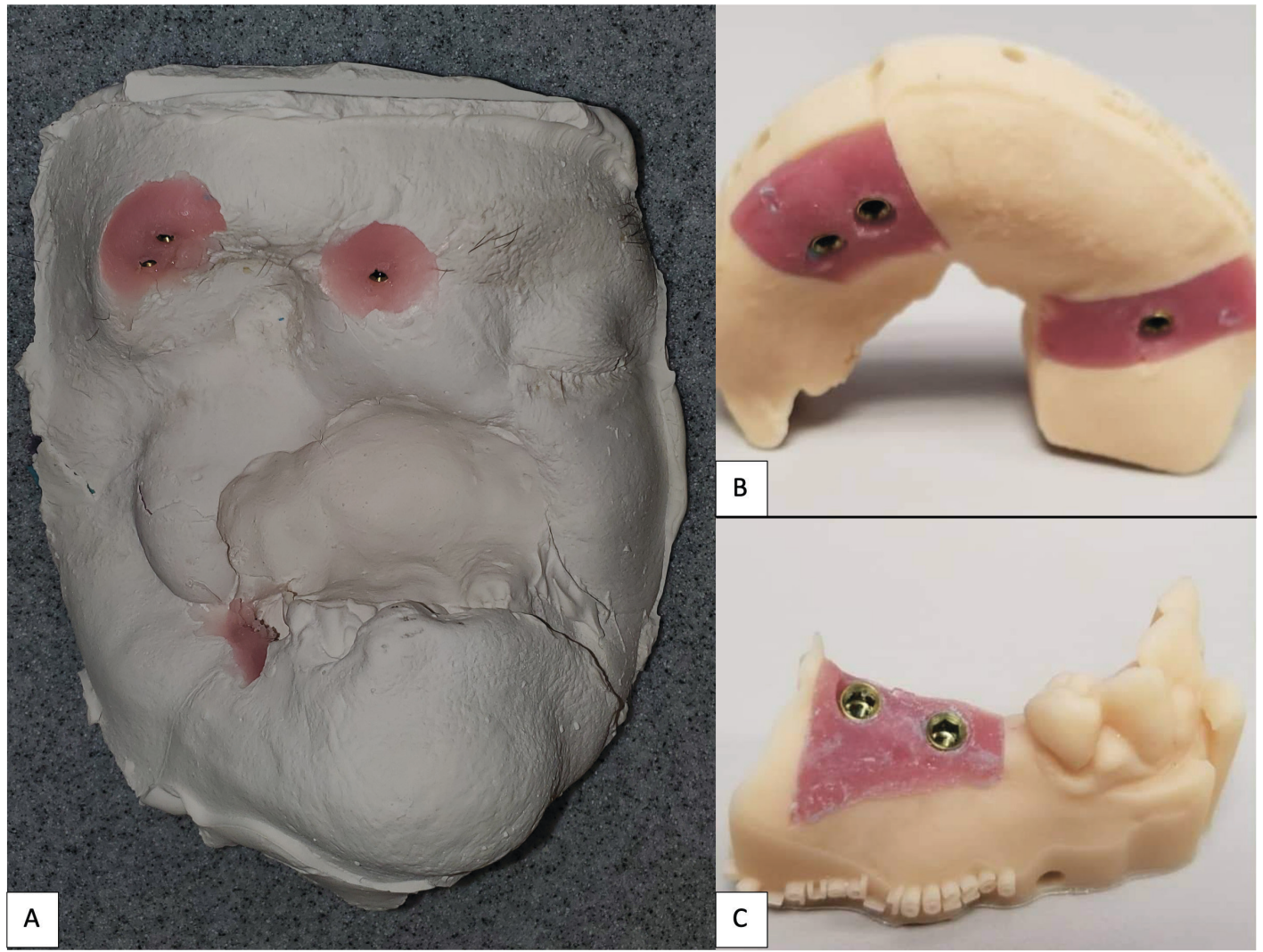

FIGURE 11. Case 3. Traditional dental stone model of the face (A). 3D-printed models of the orbital $(\mathbf{B})$ and mandibular implant sites $(\mathbf{C})$.

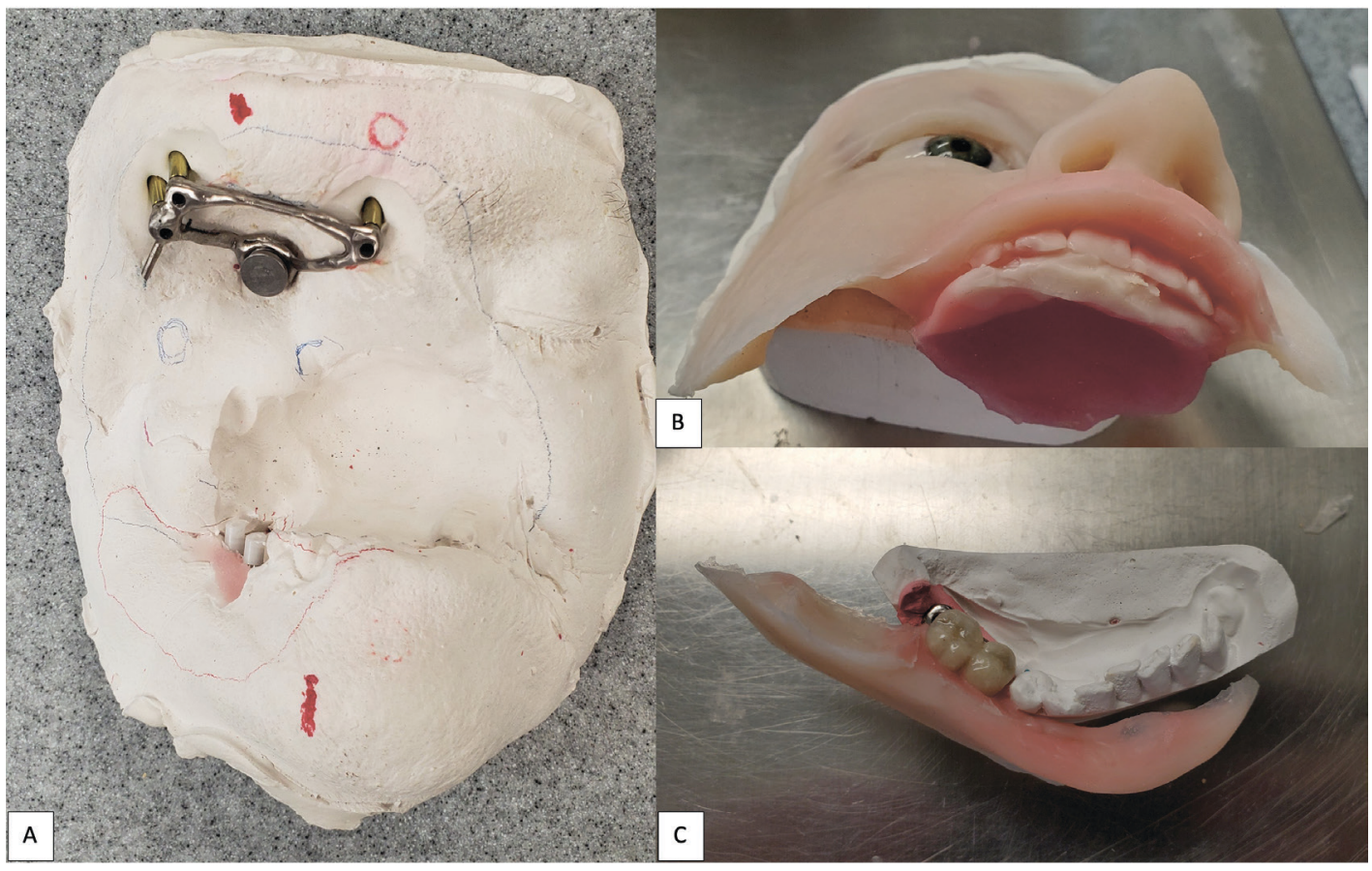

FIGURE 12. Case 3. Locator bar attachment with magnet at the medial aspect of the orbital defect $(\mathbf{A})$. The primary silicone-based facial prosthesis with the incorporation of a palatal augmentation to facilitate deglutition and articulation (B). The second portion of the prosthesis including a silicone-based lower lip incorporated into the mandibular implant locator bar attachment to facilitate mandibular movement (C). 

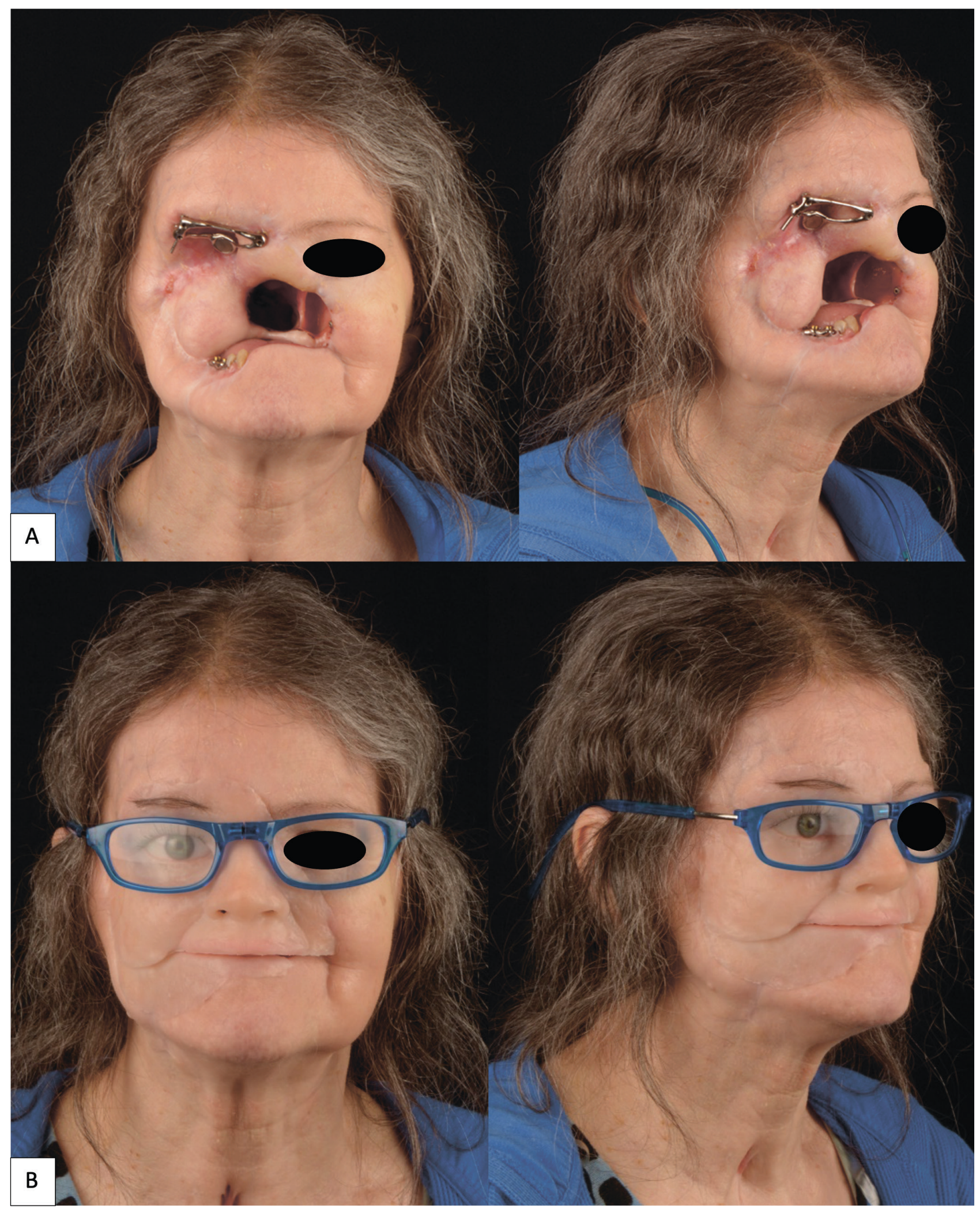

FIGURE 13. Case 3. Frontal and three-quarter views prior to (A) and after the placement of the final facial prostheses (B). 


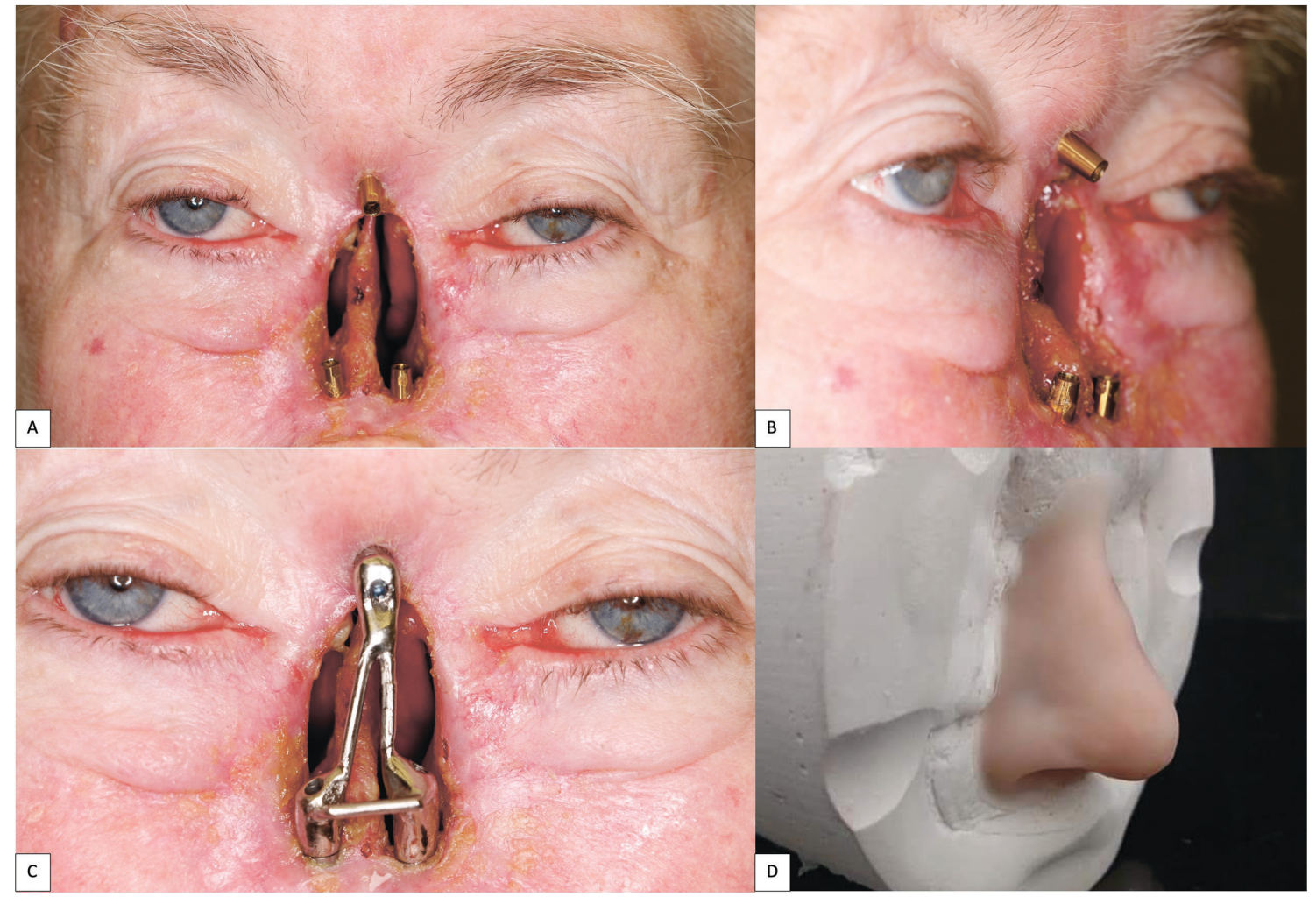

FIGURE 14. Case 4. Frontal (A) and lateral views (B) of the implants placed into the glabella and anterior maxilla. Tripod bar locator in place (C). Wax up of the prosthesis on stone cast model (D).

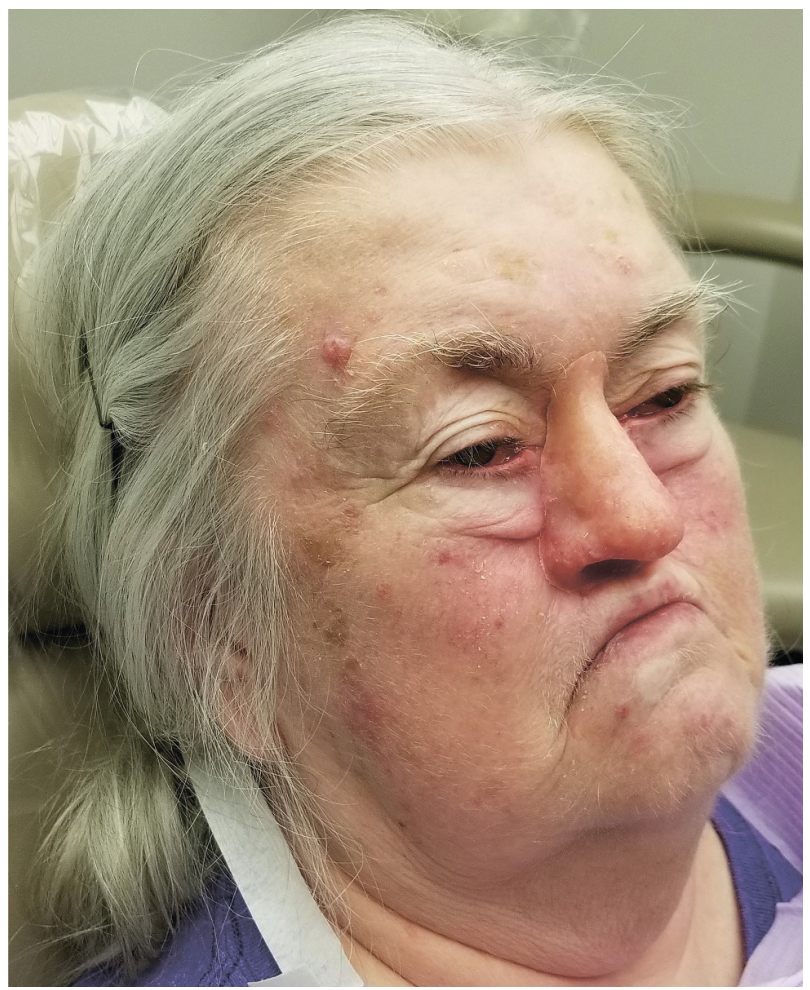

FIGURE 15. Case 4. Three-quarter view of the patient with the nasal prosthesis in place. 


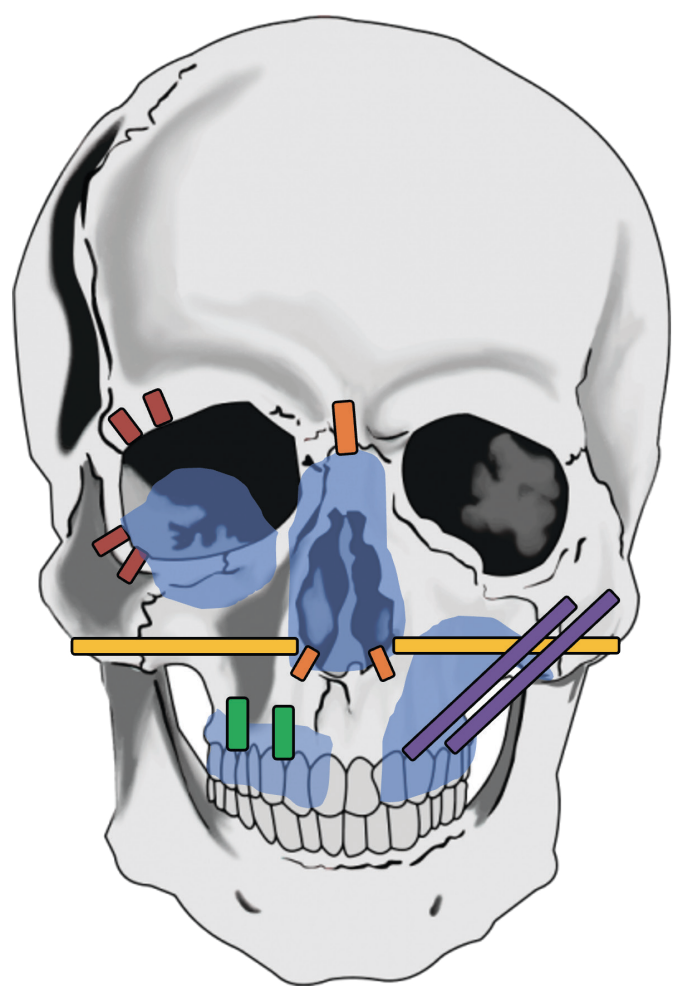

FIGURE 16. Preferred implant placement for osseointegrated implants where bone density is sufficient on CT imaging and/or intraoperatively is shown for orbital (red), isolated nasal (orange), nasomaxillary (yellow), maxillary alveolus (green), and partial maxillectomy (purple) defects. Traditional implant lengths are illustrated in red, orange, and green while longer length zygomae implants are illustrated in yellow and purple.

\section{DISCUSSION}

Midface defects resulting from ablative surgeries or trauma can be detrimental not only for the patient's psychosocial status but can also be a challenge for a reconstructive surgeon when multiple facial subunits and dentition are involved. In these cases, a maxillofacial prosthesis can provide a satisfactory outcome in terms of restoring form and oral function. Since the initial application of osseointegrated implants for dental rehabilitation, its placement in the craniomaxillofacial complex has allowed for better retention of extraoral prosthetics.

\section{Osseointegrated Implants for Dental Rehabilitation}

Since its inception in the 1970s, the predictability and success of osseointegrated implants for dental rehabilitation has dramatically improved with a survival rate of approximately $96 \%$ at 10 -years. ${ }^{22}$ Its high success rate can be attributed to the evolution in its structural design and build, biomaterial surface coating, and technical modifications at the time of placement. ${ }^{23}$ Furthermore, there continues to be ongoing studies defining clinical factors such as age, bone quality, and implant characteristics, and the long-term stability and success of osseointegrated implants to guide clinicians in selecting the right surgical candidate for a successful implant-based dental rehabilitation. ${ }^{24}$ In our practice, we provide the option for dental implant-based dental rehabilitation based on clinical factors such as the quantity and quality of the soft (keratinized mucosa) and hard (bone) tissue. Additionally, we also take into consideration the patient's medical comorbidities and social behaviors that have a negative impact on the success of the implant such as smoking and prior head and neck radiation therapy.

\section{Osseointegrated Implants for Craniomaxillofacial Rehabilitation}

Although lower than traditional intraoral implants, the overall success rate of extraoral implants varies by site location (e.g., auricular, orbital, and 
nasal) and local tissue factors. Extraoral implant survival rates are on average greater when placed into non-irradiated vs. radiated bone as shown in the existing literature ${ }^{25-27}$ with a reduction in $7 \%$ survival as shown in the most recent systematic review. ${ }^{28}$ The lower survival rate of endosseous implants in irradiated tissue are attributed to the side effects following radiation such as fibrosis, osteonecrosis, and impaired wound healing.22 Therefore, in oncologic cases where prosthetic rehabilitation is planned, osseointegrated implants are placed at the time of the ablative surgery and prior to adjuvant radiotherapy to mitigate those negative side effects. In our series (Table 1), only one patient (Case 1) received radiotherapy prior to implant placement. All the implants were successfully osseointegrated and loaded at the final facial prosthesis. With regards to implant site, the auricular region has been shown the lowest probability of failure, followed by the orbital and nasal regions. ${ }^{25,28,30,31}$

TABLE 1. Case Details at the Time of Implant Placement.

\begin{tabular}{|c|c|l|c|l|l|}
\hline Case & $\begin{array}{c}\text { Brown's } \\
\text { Defect }\end{array}$ & Prior Reconstructive Surgery & $\begin{array}{c}\text { Prior } \\
\text { Radiotherapy }\end{array}$ & \multicolumn{1}{|c|}{ No. (Size of Implants) } & \multicolumn{1}{c|}{ Location } \\
\hline 1 & IIIC & None & No & $\begin{array}{l}2(4.4 \mathrm{~mm} \times 47.5 \mathrm{~mm} \text { and } \\
4.4 \mathrm{~mm} \times 37.5 \mathrm{~mm})\end{array}$ & Bilateral zygoma \\
\hline 2 & IVD & $\begin{array}{l}\text { Latissimus dorsi free flap, fibula } \\
\text { free flap, anterior lateral thigh } \\
\text { free flap, radial forearm free flap }\end{array}$ & Yes & $3(3.8 \mathrm{~mm} \times 9 \mathrm{~mm})$ & Supero-lateral orbital rim \\
\hline 3 & IVD & Anterior lateral thigh free flap & No & $\begin{array}{l}3(3.8 \mathrm{~mm} \times 9 \mathrm{~mm}), \\
1(3.4 \mathrm{~mm} \times 10.5 \mathrm{~mm}),\end{array}$ & $\begin{array}{l}\text { Supero-lateral orbital rim, } \\
\text { alvella, right mandibular } \\
\text { alveolus, and left zygoma }\end{array}$ \\
\hline 4 & VI & None & No & $\begin{array}{l}3(3.8 \mathrm{~mm} \times 13 \mathrm{~mm}, 3.8 \mathrm{~mm} \\
\times 15 \mathrm{~mm}, 3.8 \mathrm{~mm} \times 9 \mathrm{~mm})\end{array}$ & Anterior maxilla and glabella \\
\hline
\end{tabular}

\section{Digital Technology and Maxillofacial Rehabilitation}

Within the past decade, there has also been a rapid increase in the utilization of all digital technologies in maxillofacial reconstructive surgery and prosthetics. ${ }^{32}$ The use of photogrammetry, $3 \mathrm{D}$ printing, and virtual planning has provided more accurate and predictable results as well as decreased conventional laboratory processes for complex multi-staged maxillofacial reconstructive and rehabilitation. From the surgical standpoint, the use this technology has been extremely helpful in the preoperative and intraoperative timepoints. For example, when compared to conventional reconstructive surgery, virtual surgical planning allows the reconstructive surgeon to visualize the shape and form of the underlying bone and vascular supply at the recipient and donor sites, aids in the osteotomies to optimize bone contact, and reduces the total operative time. ${ }^{1,33-35}$ With regards to the restorative (prosthetic) aspect, the incorporation of the technology reduces the manual workload, which in turn, decreases the overall cost and production time. Additionally, digital records can be quickly accessed and stored indefinitely. However, the learning curve and equipment for this innovative workflow can require greater time commitment and investment upfront. This is especially true when the workflow has not been standardized yet among laboratories and anaplastologists.

\section{Limitations and Challenges}

Our case series demonstrated a high success rate $(100 \%)$ of extraoral osseointegrated implants and incorporated several digital methods to streamline the prosthetic workflow used in the both the laboratory and chairside to optimize the clinical and aesthetic outcome of prosthetically-restored midface defects. However, this case series only shows the successful outcomes in a selected group of patients who were able to follow through with the prosthetic rehabilitation to completion. Longterm follow-up for this patient population is not feasible as these patients tend to be lost to follow- 
up after the placement of the prosthesis. Of note, all the osseointegrated implants were placed freehanded and that the angulation and number of implants placed were decided intraoperatively by the reconstructive surgeon according to the bone quantity and quality. Several challenges have been identified during the digitalization process associated with maxillofacial prosthetics. Firstly, while a desktop 3D printer is adequate for processing costs associated with intraoral defects, its application for large maxillofacial defects requires a larger and more costly printer as full-face casts may be indicated. Secondly, the dental software and manufacturer ends have not been streamlined with the specific needs for extraoral prosthetic rehabilitation. As a result, innovative or off-label approaches are often used, and requires additional time investment associated with trial-and-error processes. Finally, while the existing analog workflow has been well-established for decades, the transition to a completely digital and lab-free workflow for prosthetics may not be preferred for the traditional and experienced prosthodontist or anaplastologists. ${ }^{1}$ As digital technology continues to be incorporated more into the planning processes of maxillofacial reconstructive surgery and prosthetic rehabilitation, the clinical outcome will continue to become more reliable, reproducible, and predictable for both simple and complex midface rehabilitation.

Finally, the technologies, materials, and services provided to achieve the clinical outcomes described in this case series can be a challenge to achieve for a reconstructive surgeon outside of the academic setting where there is limited access to a maxillofacial prosthodontist with the expertise in maxillofacial prosthetics. In addition, the financial costs associated with providing this complex multi-staged treatment may not be feasible for the patient as well. Currently, there are no comparative studies demonstrating whether reconstructive surgery only versus prosthetic rehabilitation provides superior clinical outcomes. Historically, both types of treatments have been resulted with excellent aesthetic and functional outcomes. Therefore, this case series provides the reader with the basic knowledge regarding the current implant-based maxillofacial prosthetic treatment options for midface defects. Midface reconstruction and rehabilitation should be planned on a case-bycase basis with the inclusion of a multidisciplinary team of maxillofacial reconstructive surgeon and maxillofacial prosthodontist when the dentition is involved to decrease surgical morbidity and improve psychosocial well-being for the patient.

\section{ACKNOWLEDGEMENTS}

Not applicable.

\section{AUTHORS' CONTRIBUTIONS}

All authors made substantial contributions to the conception, design of the study, analysis and interpretation, composition of the manuscript, and final approval of the manuscript.

\section{FINANCIAL SUPPORT AND SPONSORSHIP}

None.

\section{CONFLICTS OF INTEREST}

All authors declared that there are no conflicts of interest.

\section{ETHICAL APPOVAL AND CONSENT TO PARTICIPATE}

IRB: 300004743 Role of osseointegrated implants in maxillofacial reconstruction. The study protocol was reviewed and approved by the University Institutional Review Board (IRB) for Human Use.

\section{CONSENT FOR PUBLICATION}

The author declares that signed Informed Consents were obtained for publication of patient's images in this manuscript.

\section{REFERENCES (35)}

1. Beumer J, Marunick MT, Esposito SJ. Maxillofacial rehabilitation: prosthodontic and surgical management of cancer-related, acquired, and congenital defects of the head and neck. 3rd edition. Quintessence Publishing Co. Inc; 2011.

2. Becker C, Becker AM, Pfeiffer J. Health-related quality of life in patients with nasal prosthesis. $J$ Craniomaxillofac Surg 2016;44(1):75-9. https://doi.org/10.1016/j.jcms.2015.10.028

3. Cobein MV, Coto NP, Crivello Junior O, Lemos JBD, Vieira LM, Pimentel ML, Byrne HJ, Dias RB. Retention systems for extraoral maxillofacial 
prosthetic implants: a critical review. $\mathrm{Br} J$ Oral Maxillofac Surg 2017;55(8):763-9.

https://doi.org/10.1016/j.bjoms.2017.04.012

4. Brown JS, Shaw RJ. Reconstruction of the maxilla and midface: introducing a new classification. Lancet Oncol 2010;11(10):1001-8. https://doi.org/10.1016/S1470-2045(10)70113-3

5. Cordeiro PG, Santamaria E. A classification system and algorithm for reconstruction of maxillectomy and midfacial defects. Plast Reconstr Surg 2000;105(7):2331-46; discussion 2347-8. https://doi.org/10.1097/00006534-200006000-00004

6. Burget GC, Walton RL. Optimal use of microvascular free flaps, cartilage grafts, and a paramedian forehead flap for aesthetic reconstruction of the nose and adjacent facial units. Plast Reconstr Surg 2007;120(5):1171-207.

https://doi.org/10.1097/01.prs.0000254362.53706.91

7. Moreno MA, Skoracki RJ, Hanna EY, Hanasono MM. Microvascular free flap reconstruction versus palatal obturation for maxillectomy defects. Head Neck 2010;32(7):860-8.

https://doi.org/10.1002/hed.21264

8. Researches $\mathrm{O}$ and Supervision T. "The glossary of prosthodontic terms." J Prosthet Dent 94.1 (2005): 10-92.

9. Brånemark PI, Hansson $\mathrm{BO}$, Adell R, Breine U, Lindström J, Hallén O, Ohman A. Osseointegrated implants in the treatment of the edentulous jaw. Experience from a 10-year period. Scand J Plast Reconstr Surg Suppl 1977;16:1-132.

10. Tolman DE, Desjardins RP. Extraoral application of osseointegrated implants. J Oral Maxillofac Surg 1991;49(1):33-45. https://doi.org/10.1016/0278-2391(91)90264-m

11. Ueda M, Hibino Y, Niimi A. Usefulness of dental implants in maxillofacial reconstruction. J Long Term Eff Med Implants 1999;9(4):349-66.

12. Goiato MC, Pesqueira AA, Ramos da Silva C, Gennari Filho H, Micheline Dos Santos D. Patient satisfaction with maxillofacial prosthesis. Literature review. J Plast Reconstr Aesthet Surg 2009;62(2):175-80. https://doi.org/10.1016/j.bjps.2008.06.084

13. Markt JC, Lemon JC. Extraoral maxillofacial prosthetic rehabilitation at the M. D. Anderson Cancer Center: a survey of patient attitudes and opinions. J Prosthet Dent 2001;85(6):608-13. https://doi.org/10.1067/mpr.2001.114758

14. Flood TR, Russell K. Reconstruction of nasal defects with implant-retained nasal prostheses. $\mathrm{Br} \mathrm{J}$ Oral Maxillofac Surg 1998;36(5):341-5.

https://doi.org/10.1016/s0266-4356(98)90644-1

15. Joseph DL, Shumrick DL. Risks of head and neck surgery in previously irradiated patients. Arch Otolaryngol 1973;97(5):381-4.

https://doi.org/10.1001/archotol.1973.00780010393005

16. Mücke T, Rau A, Weitz J, Ljubic A, Rohleder N, Wolff KD, Mitchell DA, Kesting MR. Influence of irradiation and oncologic surgery on head and neck microsurgical reconstructions. Oral Oncol 2012;48(4):367-71. https://doi.org/10.1016/j.oraloncology.2011.11.013

17. Schultze-Mosgau S, Grabenbauer GG, RadespielTröger M, Wiltfang J, Ries J, Neukam FW, Rödel F. Vascularization in the transition area between free grafted soft tissues and pre-irradiated graft bed tissues following preoperative radiotherapy in the head and neck region. Head Neck 2002;24(1):42-51.

https://doi.org/10.1002/hed.10012

18. Morrish RB Jr, Chan E, Silverman S Jr, Meyer J, Fu KK, Greenspan D. Osteonecrosis in patients irradiated for head and neck carcinoma. Cancer 1981;47(8):1980-3. https://doi.org/10.1002/1097 $0142(19810415) 47: 8<1980$ : : a id cncr2820470813>3.0.co;2-y

19. Anderson L, Meraw S, Al-Hezaimi K, Wang HL. The influence of radiation therapy on dental implantology. Implant Dent 2013;22(1):31-8. https://doi.org/10.1097/ID.0b013e31827e84ee

20. Le JM, Gigliotti J, Ying Y, Kase MT, Morlandt AB. Computer-assisted microvascular free flap reconstruction and implant rehabilitation of the maxilla-treatment of a rare post-orthognathic complication. J Maxillofac Oral Surg 2021:1-6. https://doi.org/10.1007/s12663-020-01492-y

21. Le JM, Chen PH, Seidenfaden JC, Morlandt AB, Kase MT. Zygomatic implants for restoration of complex nasal defects-a case report and outcome. J Diagn Treat Oral Maxillofac Pathol 2020;4(9):152-61. https://doi.org/10.23999/j.dtomp.2020.9.2

22. Howe MS, Keys W, Richards D. Long-term (10-year) dental implant survival: a systematic review and sensitivity meta-analysis. J Dent 2019;84:9-21. https://doi.org/10.1016/j.jdent.2019.03.008

23. Kandavalli SR, Wang Q, Ebrahimi M, Djavanroodi F, Attarilar S, Liu S. A brief review on the evolution of metallic dental implants: history, design, and application. Front Mater 2021;8:646383. https://doi.org/10.3389/fmats.2021.646383

24. Raikar S, Talukdar P, Kumari S, Panda SK, Oommen VM, Prasad A. Factors affecting the survival rate of dental implants: a retrospective study. J Int Soc Prev Community Dent 2017;7(6):351-5. https://doi.org/10.4103/jispcd.JISPCD_380_17

25. Karakoca S, Aydin C, Yilmaz H, Bal BT. Survival rates and periimplant soft tissue evaluation of extraoral implants over a mean follow-up period of three years. 
J Prosthet Dent 2008;100(6):458-64. https://doi.org/10.1016/S0022-3913(08)60265-6

26. Schoen PJ, Raghoebar GM, van Oort RP, Reintsema $\mathrm{H}$, van der Laan BF, Burlage FR, Roodenburg JL, Vissink A. Treatment outcome of bone-anchored craniofacial prostheses after tumor surgery. Cancer 2001;92(12):3045-50.

https://doi.org// $0.1002 / 1097$ 0142(20011215)92:12<3045::aid-cncr10147>3.0.co;2-k

27. Visser A, Raghoebar GM, van Oort RP, Vissink A. Fate of implant-retained craniofacial prostheses: life span and aftercare. Int J Oral Maxillofac Implants 2008;23(1):89-98.

28. ElKhashab MA, Radi IAW, Elkhadem AH. Implant prognosis in irradiated versus non-irradiated nasal, orbital and auricular sites. Int J Oral Maxillofac Surg 2020;49(5):636-48.

https://doi.org/10.1016/j.ijom.2019.09.010

29. Brook I. Late side effects of radiation treatment for head and neck cancer. Radiat Oncol J 2020;38(2):8492.

https://doi.org/10.3857/roj.2020.00213

30. Chrcanovic BR, Nilsson J, Thor A. Survival and complications of implants to support craniofacial prosthesis: a systematic review. J Craniomaxillofac Surg 2016;44(10):1536-52.

https://doi.org/10.1016/j.jcms.2016.07.030
31. Abu-Serriah MM, McGowan DA, Moos KF, Bagg J. Outcome of extra-oral craniofacial endosseous implants. Br J Oral Maxillofac Surg 2001;39(4):269-75. https://doi.org/10.1054/bjom.2000.0578

32. Elbashti ME, Sumita YI, Kelimu S, Aswehlee AM, Awuti S, Hattori M, Taniguchi H. Application of digital technologies in maxillofacial prosthetics literature: a 10 -year observation of five selected prosthodontics journals. Int J Prosthodont 2019;32(1):45-50. https://doi.org 10.11607/ijp.5932

33. Sweeny L, Fuson AR, Curry JM. Current trends in midface reconstruction and use of virtual surgical planning. Plast Aesthet Res 2021;8:18. http://doi.org/10.20517/2347-9264.2020.228

34. Resnick CM, Inverso G, Wrzosek M, Padwa BL, Kaban LB, Peacock ZS. Is there a difference in cost between standard and virtual surgical planning for orthognathic surgery? J Oral Maxillofac Surg 2016;74(9):1827-33. http://doi.org/10.1016/j.joms.2016.03.035

35. Rodby KA, Turin S, Jacobs RJ, Cruz JF, Hassid VJ, Kolokythas A, Antony AK. Advances in oncologic head and neck reconstruction: systematic review and future considerations of virtual surgical planning and computer aided design/computer aided modeling. J Plast Reconstr Aesthet Surg 2014;67(9):1171-85. http://doi.org/10.1016/j.bjps.2014.04.038 